\title{
VOCABULARIO DEL CANTÓN DE SAN RAMÓN DE ALAJUELA
}

\author{
Mainor Elizondo Morales
}

\begin{abstract}
RESUMEN
El presente artículo es el resultado del trabajo de campo hecho en San Ramón, provincia de Alajuela, Costa Rica. Utilizando métodos de campo de la dialectología tradicional, el autor recogió datos léxicos para confeccionar un diccionario regional.
\end{abstract}

\begin{abstract}
The present arcticle is the product of field work done in the San Ramón, in the province of Alajuela, Costa Rica, where the author gathered lexical data in order to write a regional dictionary, using traditional dialectological field methods.
\end{abstract}

\section{Introducción}

El presente vocabulario es el producto de una recolección de datos léxicos que surgió en un principio como parte de un proyecto de trabajo comunal realizado en el cantón de San Ramón entre 1990 y 1994, con lo cual se pretende, en primer lugar, dar a conocer aspcetos de la cultura ramonense a través del léxico particular de las comunidades que componen dicho cantón; en segundo lugar, intenta contribuir al conocimiento del léxico costarricense, distribuido por regiones. Cabe agregar que, de acuerdo con la bibliografía consultada, no existen estudios lexicográficos para dicho cantón.

\section{Metodología}

Los datos que se han reunido en este trabajo fueron extraídos mediante la encuesta indirecta en todos los distritos del cantón de San Ramón, con la ayuda del cuestionario para el Atlas lingüístico-etnográfico de Costa Rica (Quesada Pacheco 1992). ${ }^{1}$ De este cuestionario se emplearon los siguientes apartados: el cuerpo humano, el vestido, la vivienda, alimentación, fonómenos atmosféricos, topografía y naturaleza del terreno, el campo, cultivos (el café, el maíz, el frijol, la caña de azúcar, las musáceas, el tabaco), el árbol y sus productos, animales 
domésticos y no domésticos, la familia, festividades y distracciones, juegos, oficios y empleos. Por otra parte, se recopilaron datos concernientes a las malas hierbas, plantas medicinales, el trapiche, utensilios y herramientas de trabajos, enfermedades y el proceso de elaboración del dulce. Sin embargo, en lugar de trazar mapas lingüísticos, que es el fin principal de dicho cuestionario, he decidido organizar los datos alfabéticamente, ya que las respuestas que se obtuvieron en el trabajo de campo no daban indicios de estar distribuidas geográficamente. En este sentido, se puede concluir que el cantón de San Ramón representa una región bastante homogénea, al menos respecto del nivel léxico.

En lo pertinente a la selección de los datos, se hizo tomando en cuenta el concepto de costarriqueñismo -implícito o explícito- de los diccionarios a mano (Gagini 1975, Quesada Pacheco 1991), de manera que se incluyeron aquellos rubros que figuraran en los diccionarios mencionados; o bien, que no figuraran ni en los diccionarios mencionados ni en los generales de la lengua española. En casos en que la pieza léxica se registró en un determinado distrito, se indicó el lugar específico de procedencia.

Las encuestas se aplicaron a dos personas por distrito. Se utilizaron informantes de ambos sexos, sin escolaridad. En cuanto a la edad, un $15 \%$ de los informantes tenían entre 15 y 29 años, y un $85 \%$ entre 30 y 65 años. Todos los informantes eran nativos del cantón en estudio.

\section{Abreviaturas empleadas}

$\begin{array}{ll}\text { adj. } & \text { adjetivo } \\ \text { adv. } & \text { adverbio } \\ \text { f. } & \text { femenino } \\ \text { interj. } & \text { interjección } \\ \text { intr. } & \text { verbo intransitivo } \\ \text { loc. } & \text { locución } \\ \text { loc. adv. } & \text { locución adverbial } \\ \text { m. } & \text { masculino } \\ \text { pl. } & \text { plural } \\ \text { prep. } & \text { preposición } \\ \text { pron. } & \text { pronombre } \\ \text { ref. } & \text { verbo reflejo } \\ \text { tr. } & \text { verbo transitivo } \\ \text { v. pron. } & \text { verbo pronominal }\end{array}$




\section{Vocabulario}

abejón m._de café. Insecto que taladra el café.

abejoncillo m. Mata de café antes de abrirse las hojas.

abrojo m. Maleza que queda luego de la cogida del café o del maíz. //2 Nombre genérico de algunas malas hierbas, principalmente las que se adhieren fácilmente a la vestimenta del labrador.

acordonar tr. Limpiar el terreno y formar hileras con la basura o maleza. //2 Alistar el terreno para la siembra.

achucuyado adj. Desanimado, triste.

afilar tr. Sacar filo al cuchillo, ya sea con la lima o con la piedra de afilar.

agrá $\mathrm{m}$. Nombre de bejuco en cuyo tallo se almacena gran cantidad de agua, la cual es medicinal. agú $\mathrm{m}$. Comida hecha de plátanos sancochados y condimentos. Registrada en Chachagua.

agujear tr. Etapa en que el maíz empieza a nacer.

¡ah bárbaro! interj. Denota admiración ante los hechos o cualidades de una persona.

ajecho coger de _loc. Recolectar los últimos granos de la cosecha.

ajuste m. Contrato.

alburear tr. Perturbar, importunar.

al despiste loc. adv. Disimuladamente.

alegar tr. Discutir.

alentado adj. Sano, con vigor.

aletón m. Parte de la montura que evita el contacto de la pierna con la bestia.

alfajilla f. Regla de madera donde va sujeto el zinc en la construcción de las casas.

almácigo $\mathrm{m}$. Semillero.

almadiado adj. Mareado.

almorfino $\mathrm{m}$. Nombre de mala hierba que se caracteriza por tener muchas espinas.

alomillar tr. Preparar un terreno para la siembra, mediante la formación de hileras de tierra que sobresalen del terreno.

altamisa f. Nombre de planta medicinal, de flor blanca, utilizada para el tratamiento de los nervios.

alterparia f. Enfermedad del tomate que se caracteriza por enroscar la hoja y detener el crecimiento de la planta hasta destruirla.

¡allo! interj. Voz usada para espantar al caballo.

amarra f. Faja ancha utilizada para sostener el canasto a la cintura, en la recolección del café.

amarrar tr._el perro. Dícese de la persona que gusta no cancelar las deudas.

ancas f. pl. Ver polca.

andada f. Caminata. //2 Darse una_loc. Caminar por muchas horas.

angarilla $\mathrm{f}$. Especie de pila metálica utilizada para la medida del café. Generalmente, mide diez cajuelas de café.

anjijibrillo $\mathrm{m}$. Variedad de pasto. Se caracteriza por ser de poca altura y tener mucha raíz. 
anrajo $\mathrm{m}$. Vestido viejo.

añejo adj. Dícese del alimento de uno o varios días de preparado. //2 Persona que acaba de levantarse y aún no se ha duchado.

apagón m. Enfermedad del tomate que se caracteriza por marchitar las hojas y el tallo, hasta destruirlos.

apaleada $\mathrm{f}$. Paliza.

aparejo $\mathrm{m}$. Especie de montura construida de madera en forma de $\mathrm{V}$ inversa, utilizada especialmente para transportar mercadería.

aparto $\mathrm{m}$. Pequeña división territorial que se realiza en las fincas.

apazote $\mathrm{m}$. Nombre de hierba medicinal, de fuerte olor, usada en el tratamiento de parásitos.

aperos m. pl. Correaje de las caballerías.

apodar tr. Acción de cortar la planta del café a determinada altura.

aporcar tr. Cubrir el pie de una planta con tierra adicional.

aporreadero $\mathrm{m}$. Sitio donde se aporrean los frijoles.

apretado adj. Con poco tiempo y muchas obligaciones. //2 Helado hecho en una bolsa.

arado (de bueyes) $\mathrm{m}$. Instrumento metálico en forma de ganchos para remover la tierra, el cual se adhiere al yugo de los bueyes por medio de una cuerda. //2 _de disco. Herramienta que se incorpora a un chapulín. Está formada por discos que se mueven circularmente para remover la tierra.

arepa f. Torta de arina, huevos, mantequilla, leche, queso y azúcar. //2 Ver pepa.

armarse la gorda loc. Empezar una riña o discusión.

arracache $\mathrm{m}$. Nombre de un tubérculo comestible del cual se hace un tipo de comida en picadillo para bodas, fiestas populares, nueve días, etc.

arratonamiento $\mathrm{m}$. Contracción involuntaria de un músculo.

arratonarse v. pron. Sufrir contracciones musculares involuntarias.

arrecostado adj. Persona que vive a costa de los demás.

arrecho adj. Persona muy persistente en el logro de sus propósitos. //2 Persona que tiene mucha suerte.

arrepentido adj. Dícese del pelo ondulado, que no es lacio ni crespo.

¡arrimis! Interjección usada en el juego de bolinchas para indicar acercamiento.

arrojadera f. Vómitos.

aserrador $\mathrm{m}$. Persona que labora en el aserradero encargado de aserrar las tablas.

asistente $\mathrm{m}$. El encargado del Puesto de Salud.

atacado adj. Dícese de la persona que llora incontrolablemente.

atado m. Dos tapas de dulce unidas por su base.

atarrá $\mathrm{m}$. Panal, muy resistente, de abejas negras que por tener vellos en sus patas se enredan al cabello con gran facilidad.

atenido adj. Ver arrecostado.

aterro $\mathrm{m}$. Cantidad enorme de tierra que obstruye el paso. //2 Conjunto de cosas.

atilintar tr. Tensar una cuerda.

a todo esto loc. adv. A propósito: A todo esto, ya llegó Ángela.

atojar tr. Azuzar.

atracador m. Persona que gusta hacer trampa en los negocios. 
atracar tr. Hacer trampa en los negocios.

atraco $\mathrm{m}$. Acto de atracar.

atrevido adj. Dícese del hombre que gusta abusar de las mujeres. //2 Persona que gusta utilizar las pertenencias ajenas sin permiso del dueño.

aturugado adj. Repleto, lleno. //2 Dícese de la persona que está oculta en algún lugar.

aturugarse ref. Acción de ingerir gran cantidad de alimentos. //2 Ocultarse alguien en un lugar muy remoto.

avante adv. Salir_loc. Resolver una situación difícil, progresar.

averaguarse v. pron. Llenarse la ropa de manchas a causa de la humedad y por falta de ventilación.

ayotera $\mathrm{f}$. Terreno cultivado de ayotes.

azajar m. Flor del café en su última etapa de formación.

baboso adj. Tonto.

bacinilla f. Recipiente de losa o plástico utilizado para orinar o defecar.

bagazo (de caña) m. Residuo de la caña de azúcar una vez que ha sido exprimido por las moscas del trapiche.

bajura $\mathrm{f}$. Tierras bajas y planas.

balandrán $\mathrm{m}$. Vestido de la mujer, el cual es largo y viejo.

balaú m. Arma de fuego, calibre veintidós.

baldazo m. Aguacero fuerte.

balde $\mathrm{m}$. Recipiente de plástico o aluminio de forma semicónica utilizado para transportar agua o para ordeñar.

balear tr. Herir con bala.

balsa $\mathrm{f}$. Nombre de árbol cuya flor contiene una lana beige. Una vez seca su corteza es sumamente liviana y se utiliza para aprender a nadar.

bambusal $m$. Terreno sembrado de caña de bambú.

banano criollo $\mathrm{m}$. Variedad de las musáceas que se caracteriza por ser pequeño y dulce.

banco $\mathrm{m}$. Muro, generalmente de concreto, donde se colocan las masas del trapiche.

baquetas (del trapiche) f. pl. Barras de hierro que, adheridas a los durmientes, sostienen las masas del trapiche.

barbacoa f. Armazón construida para que las plantas enredaderas se extiendan sobre ella.

barbudo $\mathrm{m}$. Vainas de frijol tierno, envueltas y fritas en coliflor y huevo.

barcelisco m. Huevo muy pequeño.

barra f. Grupo de jóvenes que se reúne de manera informal para pasar el tiempo.

barrenillo $\mathrm{m}$. Enfermedad del café que se caracteriza por carcomer el grano.

barro de olla $m$. Arcilla.

batazo $\mathrm{m}$. Acierto favorable.

bateador adj. Dícese de la persona que gusta batear. 
batear tr. Tratar de adivinar o contestar usando respuestas sin estar seguro de su veracidad. Contestar una prueba al azar.

bejuco $\mathrm{m}$. Tortilla. Término en vías de extinción. //2 Cualquier planta enredadera.

beneficio $\mathrm{m}$. Instalaciones donde es llevado el café para su procesamiento.

berrear intr. Dícese del niño pequeño cuando llora mucho.

binazo $\mathrm{m}$. Chisme.

binear tr. Tratar de enterarse de los asuntos ajenos.

birra f. Cerveza.

birreada $\mathrm{f}$. Acto de beber gran cantidad de cerveza.

birrear v intr. Beber cerveza.

bizcocho $\mathrm{m}$. Pastel pequeño de harina de maíz, aliñado con queso y horneado.

blúmer $\mathrm{m}$. pl. Prenda de vestir interior de la mujer que cubre desde la cintura hasta el comienzo de los muslos.

bluyín m. Pantalón de mezclilla.

bobo adj. Tonto.

boca $\mathrm{f}$. Bocadillo que se come en compañía de bebidas alcohólicas.

bocaracá $\mathrm{f}$. Nombre de serpiente venenosa.

bodega $\mathrm{f}$. Lugar donde se almacena granos y cualquier utensilio o herramienta en servicio o mal estado.

bolados m. pl. Agarrar_loc. Obtener ideas, conocimientos para su propio beneficio. //2 En el juego de billar, inmiscuirse una persona ajena al juego con el propósito de ayudar a uno de los contendores. //3 Hacer_loc. Ayudar.

bolillero $\mathrm{m}$. Trabajador del aserradero encargado de recoger las tablas recién serradas.

bolillo $\mathrm{m}$. Carro pequeño con rodillos que en el aserrado transporta las tablas ya serradas.

bolincha $\mathrm{f}$. Bola de vidrio utilizada en el juego de canicas.

bolsa $\mathrm{f}$. Bolsillo de los pantalones. //2 ¡Cual _! interj. Denota negativa o rechazo (el domingo tiene que trabajar, ;cuál bolsa!) //3_de agua. Enfermedad del tomate caracterizada por convertir el fruto en agua y podrirlo.

boludo adj. Dícese de la persona muy caprichosa.

bonete $\mathrm{m}$. Pan dulce de forma redondeada. //2 Órgano genital femenino. Nombre humorístico.

boquilla $\mathrm{f}$. Parte de la bomba de atomizar donde se regula la presión de salida del líquido.

boreo $\mathrm{m}$. Acto de abonar los sembradíos esparciendo el fertilizante descuidadamente sobre estos.

borona $\mathrm{f}$. Migaja.

borrego $\mathrm{m}$. Persona muy obesa. //2 Especie de cerdo caracterizado por ser muy gordo y pequeño.

bosorola $\mathrm{f}$. Residuo del café una vez que ha sido colado para beberlo.

bozal $\mathrm{m}$. Cabestro.

braquiare $m$. Variedad de pasto.

brasier $m$. Sostén que utilizan las mujeres en sus pechos. Variante: tallador.

brete $m$. Trabajo, oficio.

breteador adj. Dícese de la persona que gusta de trabajar mucho.

bretear intr. Trabajar.

brocha f. Adulador.

brochazo m. Adulación. 
brocho adj. Dícese del grano que al molerlo no ha quedado fino.

broza $\mathrm{f}$. Cáscara de cualquier grano cocido. //2 Desecho. Residuo triturado del café o maíz. buchis $\mathrm{f}$. Gallina con gran cantidad de plumas sobre los oídos.

buchón adj. Dícese del individuo acaparador y egoísta.

burro adj. Tonto. //2 Grande. //3 A la hora del_loc. adv. Tarde.

burú $\mathrm{m}$. Panal de color blancuzco, cuyas avispas son muy agresivas. Se caracterizan por tener las alas amarillentas.

burumbún m. Escándalo. Riña ruidosa.

buseta $\mathrm{f}$. Vehículo de transporte colectivo más pequeño y veloz que el ómnibus.

C

cabanga f. Tristeza, nostalgia.

cabeza $\mathrm{f}$. Extremo más ancho de una tuca.

cabo m. Barilla que se adhiere al pico para su utilización en la labranza de la tierra u otras actividades.

cacique m. Nombre de árbol de corteza muy fuerte, utilizado para leña.

cacreco adj. Dícese de la persona muy vieja o flaca.

cacharpa f. Cualquier vehículo automotriz en mal estado o viejo.

cachetón adj. De mejillas grandes o abultadas.

cachimbal m. Agrupación de cosas juntas.

cachito m. Primera etapa de formación de la flor del cafeto.

cada nada loc. adv. Constantemente.

cadejos m. Figura legendaria en forma de perro que arrastra unas cadenas y asusta (para algunos) o acompaña (para otros) a los viajeros por las noches.

café m. _arábigo. Variedad de café de muy alto crecimiento. // 2 _catuaí. Variedad de café que se obtiene del cruce, entre el caturra y el mondonovo. Se adapta con mayor facilidad a las partes altas. // 3 _caturra. Variedad de café que se caracteriza porque la planta es más pequeña que la del café arábigo. //4 Chuzo del _. Raíz central y más grande de la planta del café. // 5 _criollo. Variedad de café que se caracteriza por ser más alto que el arábigo y caturra, el grano es más pequeño y las hojas más menudas. // 6 _híbrido. Variedad de café caracterizado por ser muy alto y sus granos ser grandes. // 7 _Villalobos. Variedad de café cuya particularidad es la abundancia de ramas.

cafetal m. Terreno cultivado de café.

cafetera f. Recipiente utilizado para hervir agua.

cai diecinueve $\mathrm{m}$. Variedad de tabaco.

calceta f. Gallina con plumas en las patas.

caldo m. Jugo de al caña de azúcar.

calinguero adj. Variedad de pasto que se caracteriza por crecer verticalmente y ser muy alto.

calzón $\mathrm{m}$. Prenda de vestir, interior femenina. //2 A_quitado loc. adv. Con franqueza (hablar a calzón quitado).

callejón m. Espacio que se deja entre un corte de café y otro. 
camanance m. Hueco en las mejillas.

camaronear intr. Pescar camarones.

camastro m. Armazón de madera que se coloca en alto, especialmente para cazar.

campo m. Sitio, espacio, asiento.

canasto $\mathrm{m}$. Cesta utilizada para labores agrícolas, especialmente para coger café.

cancha f. Terreno plano donde se practica el fútbol.

candela f. Hoja más nueva del plátano, aún arrollada.

canfín m. Nafta.

canfinera $\mathrm{f}$. Utensilio para alumbrar que funciona a base de líquido inflamable, especialmente canfín.

canforro $\mathrm{m}$. Sitio de difícil acceso y mucha profundidad. Principalmente terrenos montañosos y aledaños a los ríos.

cangilón m. Zanja de gran profundidad formada en un terreno por la erosión. //2 Parte más baja y hundida de un terreno.

canícula f. Período cuando se suspenden las lluvias, generalmente entre el quince de julio y el quince de agosto.

canilla f. Pierna.

canoa $f$. Estanque de madera de forma rectangular, utilizado para enfriar la miel de la caña. //2 Recipiente de madera utilizado para guardar granos.

cantina f. Establecimiento donde se vende licor.

cantinero $\mathrm{m}$. Dueño de una cantina. El que trabaja en ella.

canto $\mathrm{m}$. Extremo labrado de una tuca.

caña f._amarilla. Variedad de caña que se caracteriza por ser amarilla. // 2 _barbado. Variedad de caña que se caracteriza por ser de producción lenta. //3 _hawai. Variedad de caña de producción más rápida que la caña barbados. //4 _rayada. Variedad de caña caracterizada porque la caña es de varios colores. //5 carretada de _. Cantidad de caña que logra acomodarse en la carreta.

cañal $m$. Terreno cultivado de caña de azúcar.

cañazo m. Disparo fuerte a marco en el juego del balón pie.

capar tr. Acción de cortar la raíz principal de la planta del café cuando está en el semillero.

capitana f. Arbusto medicinal cuyos derivados son muy amargos. Se utiliza en tratamiento de dolores de estómago.

carajo m. Persona.

carao m. Nombre de árbol leguminoso de cuyas vainas se extrae una melaza que mezclada con leche se utiliza en el tratamiento de las deficiencias de hierro en las personas.

carbón m. Enfermedad de la caña que no permite que ésta crezca y la cubre de un polvo negro. carboncillo $\mathrm{m}$. Enfermedad que ataca la gallina, caracterizada por ponerse ésta negra y morir.

carbonear tr. Convencer. //2 Incitar a uno contra otro, introducir recelo.

carbunclo $\mathrm{m}$. Insecto noctámbulo que despide una luz muy fuerte e intermitente.

carbura f. Lámpara que funciona con carburo.

carga f. Voz usada entre personas jóvenes con el significado de bueno, bonito, elegante, inteligente (¡Qué carga ese pantalón!).

cargada $\mathrm{f}$. Preñada. (Usada tanto para humanos como para animales). 
cargamico m. Piña del café formada por un grano pequeño adherido a uno más grande. cargar tr. Preñar a la hembra.

carguero $\mathrm{m}$. Parte que sostiene la faja y el estuche donde se guarda el cuchillo de trabajos agrícolas. cariblanco $\mathrm{m}$. Variedad de jabalí más agresivo que el tepezcuinte que vive en manadas y en estado salvaje.

carraspa f. Costra que se le forma a los utensilios de cocinar como consecuencia de que se queman los residuos de los alimentos.

carrero $\mathrm{m}$. Persona que labora en el aserradero estableciendo las dimensiones de la madera. carretillo m. Carretilla metálica.

carriel m. Cartera o bolso colgante de las mujeres.

carril m. En la tapa de frijoles, señal que se hace para dividir el campo que se va a regar.

carro m. Automóvil.

carterear tr. Hurtar carteras.

cascabela $f$. Serpiente de cascabel.

cascarudo adj. Desvergonzado.

casorearse ref. Casarse.

casquillo $\mathrm{m}$. Herradura.

catano $\mathrm{m}$. Variedad de perico cuyo copete es amarillo.

catizumba $\mathrm{f}$. Cantidad de personas o cosas generalmente utilizada para los niños.

catre $\mathrm{m}$. Cama construida de hierro y de resortes que funcionan como compresores.

catrín $m$. Vestimenta nueva.

catrinearse ref. Vestirse elegantemente.

cebolla f. Cabeza; término humorístico.

cedro $\mathrm{m}$. Nombre de varios árboles de la familia de las meliáceas.

Cegua $\mathrm{f}$. Figura legendaria que se aparece a los hombres por las noches como una mujer hermosa, pero luego su cara toma la forma de la de un caballo.

celaje m. Enfermedad del tabaco caracterizada por interrumpir el desarrollo de la hoja.

cele adj. Fruto que no ha llegado a su etapa de madurez.

cenízaro m. Nombre de árbol maderable, se utiliza sobre todo en la construcción de muebles.

cepillador $\mathrm{m}$. Trabajador del aserradero que se encarga de pulir la madera con un cepillo.

cerca $\mathrm{f}$. Cercado de palos o postes y alambres de púas.

cerote $\mathrm{m}$. Parte de la materia fecal de los humanos.

ciclón $\mathrm{m}$. Dícese de la persona o animal que tiene un solo testículo.

cigarrillo m. Planta pequeña muy común en los potreros, se caracteriza por tener la flor amarilla en forma de cigarro. Su aroma es semejante al de la menta.

cimbre m. Vibración fuerte.

cinchonazo m. Latigazo.

clavear tr. Alterar, reclamar.

cloch $\mathrm{m}$. Embrague.

coco adj. Rapado.

cochino m. Agarrado, tacaño.

cola f. _de venado. Especie de pasto cuya característica principal es crecer verticalmente a gran altura y echar una flor de color café en forma de cola. //2 Modo de sujetar el cabello las mujeres. 
colgar tr. _las tenis loc. Morir.

coligallar tr. Buscar oro en las vetas.

coligallero $\mathrm{m}$. El que busca y procesa el oro en forma artesanal.

colita $\mathrm{f}$. Coxis.

colocho m. Viruta de la madera.

color m. Lo mismo que pacho.

coloradilla f. Especie de garrapata diminuta, que se encuentra generalmente en los cafetales, de color rojizo que se introduce en la piel y causa comezón.

coludo m. Variedad de perico cuya característica principal es el gran tamaño de cola.

comal $f$. Mujer que gusta de visitar mucho la casa de los vecinos.

comedera $\mathrm{f}$. Comida en abundancia. //2 Provisiones, alimento diario que consume una familia.

comedero $\mathrm{m}$. Alimento que se coloca a los animales salvajes para cuando ellos llegan a comer cazarlos.

comodidoso adj. Persona que gusta tomar las cosas ajenas para su beneficio.

concertada adj. Dícese de la mujer que brinda servicios domésticos.

concierto m. Empleo. Servicio doméstico que brindan las mujeres.

concretera f. Lugar donde se fabrica concreto.

concreto $\mathrm{m}$. Mezcla de cemento, arena y agua.

con güevos loc. adv. Con fuerza.

consumida f. Zambullida.

contentera f. Júbilo impetuoso.

copan $m$. Variedad de tabaco.

copete rojo $\mathrm{m}$. Variedad de perico de mayor tamaño que el zapoyol, su copete es rojo.

copita f. _de café. Etapa en que la planta de café está en dos hojas y forman una especie de copa. copo $\mathrm{m}$. Parte superior de la planta de café.

corcor adv. Beber todo de una sola vez.

cordón m. Coyunda utilizada para atar el estuche del cuchillo de pretina a la cintura.

corona $\mathrm{f}$. Hoja superior de la planta de tabaco.

corronchoso adj. Aspero, duro.

corvetas adj. De piernas arqueadas.

cosco m. Golpe dado, con la mano cerrada, en la cabeza.

cosecha f. _inverniz. Producción de un cultivo, generalmente maíz y frijol, en la época de invierno. _veraniega. Producción de un cultivo, aprovechando las últimas lluvias para que nazca y luego se continúa su crecimiento por medio de regadíos.

cospó m. Penúltima etapa en el desarrollo del maíz, el cual no está duro pero tampoco tierno.

costilla f. Primeros cortes de una tuca para cuadricularla.

costroso adj. Sucio.

costurear tr. Coser.

cresta f. _tomate. Dícese de la cresta muy roja y aplastada. //2 crestón. Dícese de la cresta doblada.

creyensa f. Superstición.

creyensero adj. Supersticioso.

cristóbal m. Nombre de árbol maderable. 
cruceta f. Cuchillo largo y angosto con una cruz en el puño, que sirve de guarnición. Se usaba generalmente como arma. Voz en vías de extinción.

cuadra f. Manzana cuadrada. //2 Distancia de cien varas de una esquina a la otra.

cuadrado $\mathrm{m}$. _criollo. Variedad de musácea que se caracteriza por ser de gran altura y su producto más grande. //2 _felipita. Variedad de musácea que se caracteriza por ser pequeña, de sabor parecido al plátano verde.

cuajada $\mathrm{f}$. Leche agria.

cuatro $\mathrm{m}$. Moneda de cincuenta céntimos.

¡cuba! Voz usada para azuzar a un perro.

cubierta $\mathrm{f}$. Estuche de cuero utilizado para guardar el estuche de pretina.

cubierto $\mathrm{m}$. Cuchillo de mesa.

cucaracho $\mathrm{m}$. Nombre de árbol maderable de gran tamaño.

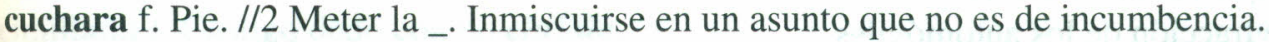

cucharilla f. Nombre de planta enredadera utilizada en la construcción de canastos.

¡cuche! interj. Voz usada para espantar al cerdo.

cuchilla f. Interjección del fluido eléctrico.

cuchillo m. _de apodar. Instrumento metálico de labranza, pesado, cuya forma es corta y ancha.

Se utiliza para apodar el café y los arbustos en general. / _de cintura (de pretina). Herramienta de labranza que se lleva colgando de la cintura, utilizado para cualquier tarea agrícola.

cuechazo m. Salivazo. //2 Trago de licor.

cuerda f. Dar_loc. Piropear.

cuero m. _de sapo. Cartera que usa el hombre (registrada en San Pedro).

cuidandero $\mathrm{m}$. El encargado de cuidar una finca.

cuita $f$. Excremento de las aves.

culantro $\mathrm{m}$. Trasero.

culazo $\mathrm{m}$. Persona de alcurnia o que cree serlo. //2 Orgulloso, presumido.

culear intr. Tener relaciones sexuales.

culiolada f. Majadería, necedad. Jerga juvenil.

culiolo m. Homosexual. También es un vocativo despectivo para los hombres.

culto $\mathrm{m}$. Establecimiento religioso de una iglesia no católica.

cundido adj. Lleno, repleto.

curraré $\mathrm{m}$. Variedad de plátano. Se caracteriza por ser más resistente a las enfermedades.

curré m. Nombre de tucanes.

cursiado adj. Dícese de la persona que está con diarrea.

curtiembre f. Suciedad.

cusuco m. Armadillo.

cutacha f. Ver cruceta.

cuyeo $\mathrm{m}$. Nombre de pájaro noctámbulo de color café y cuijen, su nombre se debe al sonido que emite. Según la creencia no se debe seguir a un cuyeo porque pierde a la persona (la desvía del camino). 


\section{CH}

chafirra f. volar_loc. Utilizar el cuchillo para apodar plantas, cortar pastos y chapear. chamba f. Trabajo por poco tiempo.

chambear intr. Trabajar en un lugar y otro.

chambón adj. Grosero. //2 Sin cualidades para realizar determinado trabajo o acción.

chamol m. Nombre de tubérculo comestible.

chancar tr. Quitar la pulpa al grano de café.

chance $\mathrm{m}$. Oportunidad. //2 En plural: lotería que se vende durante la semana y se sortea martes $\mathrm{y}$ viernes.

chancero adj. El que vende chances.

chancha f. Doble tracción de los automóviles.

chanchada f. Mala acción, desacierto.

chanchera f. Encierro para cerdos.

chanfle $\mathrm{m}$. Curva que toma una bola en el aire o en la mesa de billar.

chante m. Casa, hogar.

chapa $\mathrm{f}$. Moneda. //2 Chambón.

chapia f. Corta de la maleza a baja o mediana altura.

chapear tr. Acción de realizar la chapia.

chapulín m. Langosta de color verde, se alimenta de hojas del árbol conocido como güitite. //2 Tractor pequeño sin orugas, generalmente utilizado para arar el terreno mediante la incorporación del arado de discos, y para transportar productos.

chapulinada $\mathrm{f}$. Cantidad grande de niños.

chapulinazo $\mathrm{m}$. Golpe que se da con el dedo índice, tras formar un círculo de éste con el pulgar y luego dispararlo fuertemente.

chaqueta $\mathrm{f}$. Sudarse la_loc. Trabajar fuerte.

charral m. Campo cubierto de arbustos.

chasparria f. Enfermedad que destruye las hojas o los frutos de cultivos como café, frijol, caña y otros.

chavalo $\mathrm{m}$. Muchacho.

chaveta $\mathrm{f}$. Herramienta utilizada para esbajerar las musáceas cuya forma es semejante a la letra ese en forma vertical, con filo en los dos extremos.

chayotera $\mathrm{f}$. Mata de chayotes. Plantación de chayotes. //2 La firma.

cheque $\mathrm{m}$. El encargado de chequear.

chequear tr. Revisar (por ejemplo, controlar cuántas personas viajan en un autobús).

cherenga $f$. Guatusa.

chereveco $\mathrm{m}$. Cosa vieja.

chía $\mathrm{f}$. Avispa negra muy agresiva que vive en forma aislada.

chicasquil $\mathrm{m}$. Nombre de árbol cuyas hojas tiernas son comestibles.

chicha f. Enojo, rebeldía, mal humor. //2 ¡Qué _! Interjección que denota enojo por algo que pudo haberse realizado o no puede realizarse. 
chicharrón m. Producto que toma la forma de plástico derretido y frío, que se obtiene tras haber tomado una pequeña cantidad de miel de la caña de azúcar para determinar si está en el momento de ser pasada a los moldes.

chicharronearse ref. Quemarse las hojas o frutos debido a la chasparria.

chiche adj. Fácil de realizar.

chichoso adj. Persona que con frecuencia está de mal humor.

chiflón m. Corriente de viento que entra por una ventana.

chifonier $\mathrm{m}$. Mueble de madera, con varias gavetas y un espejo, especialmente para guardar ropa.

chilate $\mathrm{m}$. Charco. //2 Comida acuosa que se le da a los cerdos. //3 Juego que se practica sobre todo en el campo; consiste en pintar el corazón del grano de maíz y luego se lanzan. Se sigue el mismo mecanismo que en los dados.

chilillada f. Castigo dado con un chilillo.

chilillazo adj. m. Golpe dado con un chilillo.

chilillo $\mathrm{m}$. Rama delgada y sin hojas que se usa como látigo.

chilindrín m. Sonaja.

chilote m. Mazorca en su primera etapa de formación aún sin los granos desarrollados.

chillarse ref. Avergonzarse, sonrojarse.

;chillo! Interjección usada para llamar al perro.

chimado adj. Dícese de la persona intrigada.

china $f$. Niñera.

chinamo m. Establecimiento provisional que se construye en la calle.

chineado adj. Consentido, delicado.

chinear tr. Consentir, mimar. //2 Arrullar un bebé.

chineazón f. Trato excesivo y delicado para alguien, en particular para los niños.

chineo $\mathrm{m}$. Acción de chinear.

chinga f. Colilla de cigarro. //2 Cabezal de un camión.

chingar intr. Fastidiar.

chinilla $\mathrm{f}$. Tela de cuadros pequeños colocados en forma alterna.

¡chino! interj. Voz usada para llamar al cerdo.

chiquearse ref. Ufanarse, presumir.

chira f. Espata del plátano.

chiricana $\mathrm{f}$. Gallina sin plumas en el pescuezo.

chirola f. Cárcel.

chirote m. Parte que une la china con el virote, en las plantas musáceas.

chirotear intr. Pasar el tiempo sin hacer nada provechoso.

chirrisco adj. Diminuto.

chirrite m. Aguardiente de caña de azúcar y una levadura de maíz o frijoles y nances preparado clandestinamente.

chisa f. Ardilla.

chispa $\mathrm{f}$. Inteligencia, capacidad para resolver o actuar.

chispisa f. Llaga.

¡chit! Voz usada para espantar al perro. 
chiva f. ¡Qué _! loc. Elegante, bonito: ¡qué zapatos más chiva! chocado adj. Ver chimado.

chócola f. Nombre de juego con las canicas.

cholpa f. Cárcel.

cholo m. Bola de color blanco o negro exclusiva para golpear a las demás en el juego de billar. ¡cholo! interj. Voz usada para llamar al caballo.

choricear tr. Realizar un negocio poco lícito. Revender objetos a veces de dudosa procedencia. choricero $\mathrm{m}$. Quien se dedica a choricear.

chorizo m. Negocio ilícito.

chorpa f. Cárcel.

chorriada $\mathrm{f}$. Torta frita de maíz tierno.

choza $f$. Casa.

chucuyo $\mathrm{m}$. Especie de cotorra pequeña que se caracteriza por no imitar la voz humana.

chuchinga $\mathrm{f}$. Hombre que gusta pelear o discutir con las mujeres o los niños.

chuica $\mathrm{m}$. Trapo viejo.

chuletear tr. Ver estuzar.

chuminos m. pl. Dinero.

¡chumpulún! Ideófono que indica la acción de irse a un hueco, vacío o poza de agua.

chupeta f. Pezón de hule que se coloca a los niños para que se distraigan y no lloren.

chupetazo $\mathrm{m}$. Beso.

chupón m. Pezón de hule que se adhiere a un recipiente pequeño de plástico o hule utilizado para amamantar.

churraco m. Axila.

churristate $\mathrm{m}$. Nombre de mala hierba utilizada para alimentar los conejos.

\section{D}

descansar intr. Fallecer.

deschave $\mathrm{m}$. Desorden (jerga juvenil).

desecho $\mathrm{m}$. Camino o trocha que reemplaza a uno viejo y es más corto que éste.

deshojadero $\mathrm{m}$. Ver chaveta.

desmoletado $\mathrm{m}$. desmuletada. f. Persona que no tiene dientes.

desojal $\mathrm{m}$. Instrumento musical para esbajerar plátano.

desparasitante $\mathrm{m}$. Cualquier elemento tóxico que se aplica para desparasitar.

desparasitar tr. Eliminar los parásitos de los animales domésticos mediante la aplicación de un desparasitante.

despuntador $\mathrm{m}$. Trabajador del aserradero, encargado de dar la medida del largo de la madera. desramar tr. Quitar las ramas altas de los árboles para que entre la luz solar en el cafetal. desvestir tr. Desnudar.

desyerbar tr. Eliminar la maleza del sembradío de maíz.

diablillo $\mathrm{m}$. Herramienta utilizada para múltiples usos en la construcción de cercas. Tiene forma de tenaza que corta, saca grapas y sirve para clavar. 
diario m. Provisiones que se compran regularmente en los hogares.

¡diay!, ¡yay! Interjección que denota duda, admiración y para introducir los discursos.

dientón adj. Dícese de la persona que tiene los dientes grandes.

¡Dios guarde! ¡Dios libre! Interjección usada para expresar el deseo de que algo no suceda.

directorio m. Guía telefónica.

dormida f. Posada.

dormilona f. Mala hierba que cierra sus hojas por las noches o al ser tocadas. La semilla se usa para los dolores de muela, por su acción sedante.

dundo adj. Aturdido.

durmiente $\mathrm{m}$. Palo colocado en forma transversal donde se coloca la tuca para ser aserrada.

\section{$\mathbf{E}$}

echado adj. Lento, perezoso.

elote $\mathrm{m}$. Mazorca tierna de maíz.

embarcador m. embarcadora f. Que gusta de embarcar.

embarcar tr. Involucrar en una situación difícil, meter en un engaño.

embarrado adj. Inmiscuido, que a tomado parte.

embarrialar tr. Llenar de barro.

embrocar tr. Colocar un objeto boca abajo.

embrocarse ref. Dícese la persona que se coloca boca abajo. // 2 Caballo que cae al doblársele las patas delanteras.

empabilar tr. Amarrar las hojas del tabaco.

empanzado adj. Lleno.

empunchado adj. Esforzado, que trabaja fuertemente.

encabar tr. Acción de colocar el cabo a diferentes herramientas agrícolas.

encandiladora $\mathrm{f}$. Utensilio empleado por los cazadores en la noche para deslumbrar la presa.

encandilar tr. Cazar por la noche utilizando la encandiladora.

enculado adj. Enamorado.

enchanchar tr. Poner la doble tracción a un vehículo.

enchilado adj. Intrigado, Picado.

enchiloso adj. Dícese de los alimentos condimentados con picantes.

enchiquerar tr. Encerrar a un animal. // 2 Encarcelar.

encholpar tr. Ver enchiquerar (acepción 2).

enfiebrado adj. Entusiasmado, aficionado, fanático.

enganchado adj. Enamorado.

engomado adj. Dícese de la persona que tiene molestias al día siguiente de una borrachera. engringolarse ref. Entretenerse, apegarse a algo, entusiasmarse.

engripado adj. Dícese de la persona que tiene gripe.

enjachar tr. Hacer frente a alguien cara a cara.

enjaranarse ref. Endeudarse.

enllavar tr. Cerrar con llave. 
enneblinarse ref. Llenarse de neblina o nubes.

entrador adj. Decidido. (referente a aspectos amorosos)

entrecalle f. Separación entre una era y otra.

entremedio $\mathrm{m}$. Ver aparto.

entresacar tr. Acción de discriminar entre los productos agrícolas, aquellos que están listos para su recolección.

esbajerar tr. Quitar las hojas inservibles del plátano.

esbasurar tr. Eliminar las basuras de un terreno.

escachazar tr. Quitar los residuos de la caña presentes en el caldo, una vez que está en su primera etapa de producción del dulce.

escampar intr. Protegerse de la lluvia.

escarche m. Llovizna.

escarpín $m$. Zapatito tejido en lana para niños de meses.

escobilla $\mathrm{f}$. Instrumento formado de las ramas de algunas plantas, en forma de cepillo, utilizado para limpiar la canoa del dulce.

escoger tr. Apartar, entresacar los granos o frutas sanos de los inservibles.

escondido m. Jugar_. Jugar al escondite.

escornetado adj. Rápido, veloz (ir escornetado).

escuadra f. Pistola que tiene forma de escuadra. // 2 Órgano genital masculino.

eschilampado adj. Veloz, rápido.

esfondarse ref. Hundirse.

esgonzar tr. Desmayar.

eslanar tr. Quitar la lana del cafeto.

esmuletado adj. Dícese de la persona que no tiene dientes.

espadín m. Cuchillo largo y curvo en la punta. Se utiliza principalmente para la riega del frijol y la chapia.

espalmar tr. Sacar filo por primera vez al cuchillo.

espanto m. Fantasma. // 2 Pesona muy fea.

espavel $\mathrm{m}$. Nombre de árbol maderable cuyo fruto es comestible.

espeque $\mathrm{m}$. Varilla con punta utilizada en las labores agrícolas para sembrar granos.

espequear tr. Hacer hoyos con el espeque para la siembra.

espergear tr. Esparcir.

espiar, ispiar tr. Mirar. Registrada en personas mayores y en zonas rurales.

espinilludo adj. Con muchas espinillas.

espinoso adj. Con muchas espinas.

espuela f. Espolón de las aves. // 2 Experiencia en asuntos amorosos.

esqueleto $\mathrm{m}$. Mover el_loc. Bailar.

esterilla $\mathrm{f}$. Pedazo de manta o cobija que sirve de pelero a las bestias.

estilar intr., ref. Mojarse. Empaparse.

estorrentado adj. Que está lejos de su sitio. Que no quiere regresar.

estrellal $\mathrm{m}$. Terreno sembrado de zacate estrella.

estribos m. Parte de la montura donde se colocan los pies. // 2 Perder los_loc. Enojar sin control. 
estrilar tr. Molestar, importunar, reclamar constantemente.

estuzador m. Instrumento de madera, metal o hueso, utilizado para quitar la tuza al maíz. // 2 Persona encargada de estuzar el maíz.

estuzar tr. Quitar la tuza a la mazorca de maíz.

extrañar tr. Echar de menos.

\section{$\mathbf{F}$}

facha f. Presentación o actuación personal ridícula. Expresión usada únicamente con sentido peyorativo.

fachentada f. Orgullo.

fachento adj. Orgulloso.

faifa f. Órgano genital de la vaca.

faja $\mathrm{f}$. Tira utilizada para amarrar el canasto a la cintura. // 2 Gancho de la _. Parte de la faja que sirve para ajustar ésta a un extremo y otro del canasto.

fajazo $\mathrm{m}$. Azote dado con una faja.

fajina $\mathrm{f}$. Trabajar fuertemente. // 2 Sacar una _loc. Batirse a golpes con otro; pelea.

falda $\mathrm{f}$. Parte interior de la camisa que se mete dentro de los pantalones.

fandango $\mathrm{m}$. Terreno pantanoso.

fanega $\mathrm{f}$. Medida de capacidad equivalente a 20 cajuelas de café o a 25 de maíz.

fanfan m. Utensilio usado para avivar el fuego, construido con plumas. También se utiliza para ventear frijoles. Registrado en Chachagua.

farallón m. Precipicio.

feria f. Obsequio que el vendedor da a su cliente.

fierro $\mathrm{m}$. Herramienta de trabajo.

filazo m. Golpe dado con el cuchillo. // 2 Insinuación, indirecta.

filo m. Hombre.

finquita $\mathrm{f}$. Propiedad rural destinada a labores agrícolas o ganaderas.

fisga $\mathrm{f}$. Cuchillo desgastado.

fius m. Fusible.

flecha $\mathrm{f}$. Instrumento de madera en forma de $\mathrm{Y}$, con dos ligas de hule atadas a cada extremo y unidas a un pedazo de cuero cuadrado donde se coloca la piedra. Es utilizada para cazar pájaros y reptiles pequeños. // 2 Persona muy flaca.

flete $\mathrm{m}$. Transporte de mercadería el cual debe ser remunerado.

foco $\mathrm{m}$. Linterna que funciona con baterías. // 2 Dícese de los granos que toman olor al humo de la cocina al ser cocinados.

fogón $m$. Artefacto que sirve para cocinar con leña, formado con dos o tres piedras o con una plantilla.

fondeado adj. Que tiene mucho dinero.

fondillo $\mathrm{m}$. Trasero.

fondo $\mathrm{m}$. Lugar donde se lleva los animales domésticos que están en propiedad ajena o en propiedad pública. Voz en vías de desaparición ya que la ley cambió. 
foquis $\mathrm{m}$. Trasero, ano.

fortuna $\mathrm{f}$. Mancha blanca que se forma en la uña.

fregado adj. Enfermo. // 2 Pícaro, bribón.

fresa adj. Invariable. Ver plástico.

frijol m. _chileno. Variedad de frijol que se caracteriza por ser rojo y su fruto grande. // 2 chimbolo. Variedad de frijol de color negro, planta pequeña y grano redondo. // 3 _chingo. Variedad de frijol que se caracteriza por ser su planta pequeña y de muy buena producción. // 4 _negro. Variedad de frijol cuya característica principal es ser de color negro intenso. // 5 _quiubra. Variedad de frijol que se caracteriza por la gran extensión de sus bejucos y sus vainas grandes. De color rojo y grano grande. // 6 _vallo. Variedad de frijol, cuyo color oscila entre blanco y gris.

frijolar m. Campo cultivado de frijol.

frijoles m. pl. amarrar _. Atar las matas de frijol por el pie, una vez hechos los royos. // 2 aporrear_. Extraer el frijol de las vainas secas, al golpear las matas una vez arrancadas. // 3 asolear _. Exponer los frijoles al sol para eliminar su humedad. // 4 escoger _. Extraer los frijoles en mal estado; dejando los que tienen buena calidad. // 5 riega de . . Acción de sembrar los frijoles mediante su esparción sobre el terreno. // 6 _cuerudos. Momento en que los frijoles están húmedos y se dificulta su extracción de las vainas.

fritear tr. Freír.

frito $\mathrm{m}$. Sopa que se realiza de la cabeza y las entrañas del cerdo.

fuercearla loc. Esforzarce en el logró de algún propósito.

fuete $\mathrm{m}$. Látigo. // 2 Volar_. Tener relaciones sexuales.

furris adj. Situación difícil.

fusil $\mathrm{m}$. Trasero, ano.

\section{G}

gabetear tr. Variante de huequear.

gacilla $\mathrm{f}$. Prensa ovalada de seguridad.

gafear intr. Cojear una caballería por falta de herradura.

gafo adj. Dícese de la caballería que cogea por falta de herradura.

gajo $\mathrm{m}$. Cosa vieja.

gallina f. Cabeza. // 2 Cantar la_loc. Tener la mujer la autoridad. // 3 adj. Cobarde.

gallinita $\mathrm{f}$. Flor del frijol antes de abrirse. Su nombre se debe a la forma de la flor.

gallo $\mathrm{m}$. Flema. // 2 Tipo de comida formado de una tortilla caliente con frijoles, en forma de bola.

gamarra f. Cabeza.

gancho m. Sinónimo de palo de piso.

garabato $\mathrm{m}$. Palo con una curva en uno de sus extremos que forma un gancho utilizado en las labores agrícolas para recoger la maleza que se va cortando.

garacho $\mathrm{m}$. Dícese del caballo que aún no se ha capado.

garrapatiento adj. Que tiene muchas garrapatas.

garrobo $\mathrm{m}$. Especie de iguana de menor tamaño. 
garuar intr. Lloviznar.

garuarse ref. Esponerse a una garúa.

gata $\mathrm{f}$. Instrumento para levantar automóviles u objetos pesados.

gavilán $\mathrm{m}$. Nombre de árbol de corteza muy fuerte y hoja menuda..

gaza $\mathrm{f}$. Rueda de alambre utilizada para sostener un portillo y que permanezca cerrado.

golpe cortar de _. loc. Derribar bruscamente y en el primer intento una rama o arbusto utilizando un cuchillo o machete. Variante: cortar de un machetazo.

gollete m. Argolla de bejuco o metal que se coloca en la parte superior del canasto, al cual se adhieren los parales para darle macicez al tejido.

goma $\mathrm{f}$. Sensación de malestar luego de una borrachera.

gorrazo m. Golpe a traición.

gorrear tr. Golpear a traición.

gorrero adj. Que gusta gorrear.

gorrión m. Colibrí.

granea f. Época en que se recolectan los primeros granos de café.

granear tr. Recolectar los primeros granos de la cosecha del café. Seleccionar y extraer los granos más maduros del cafeto.

grano m. _cuajado del café. Fruto del cafeto que logró alcanzar el grado óptimo de desarrollo. greifrut m. Nombre de árbol y de su fruto, un cítrico de sabor amargo y ácido.

grifa $f$. Marihuana.

grifo $m$. Dícese del que fuma marihuana. // 2 Herizado.

gringo adj. Originario de los Estados Unidos de Norte América.

guaba f. Árbol de la familia de las fabáceas, cuyo fruto es comestible y en forma de vaina.

guaco $\mathrm{m}$. Ave de color amarillo cuyo nombre se debe al sonido que emite.

guachear tr. Mirar, observar. Jerga juvenil.

guachipelín m. Nombre de árbol maderero cuya corteza es muy resistente. Se utiliza para postes.

guacho $\mathrm{m}$. Lo mismo que garrobo.

guápil $\mathrm{f}$. Dos frutos unidos.

guapinol m. Nombre de árbol maderable y de su fruta que es comestible.

guaria f. Planta orquídea cuyas variedades más comunes son la morada y la blanca.

guarumo m. Nombre de árbol alto y delgado, da hojas en forma de estrella, cuya característica principal es ser hueco su tronco, donde anidan muchos insectos.

guata f. Agua. Jerga juvenil.

guatearse ref. Bañarse. Jerga juvenil.

guayabas m. pl. Los ojos. Variante: guachos.

güevasal $\mathrm{m}$. Muchas cosas en conjunto.

güevazo $\mathrm{m}$. Golpe.

güevearse ref. Trabajar fuerte.

güevo $\mathrm{m}$. Dinero. Jerga juvenil.

güija $f$. Nombre de juego ocultista.

güila $f$. Niño, niña.

güilada $\mathrm{m}$. Proceder infantil.

guinche $\mathrm{m}$. Grúa. 
guindado adj. Dícese de la persona que gusta ir detrás de otros sin ser invitado.

guindar tr. Colgar.

guineal m. Campo sembrado de guineo.

guineo m. Variedad de plátano de menor tamaño que éste. // 2 negro. Variedad de plátano cuya característica principal es el color negruzco del vástago. Se utiliza para combatir la anemia. güísaro $\mathrm{m}$. Arbusto muy parecido al guayabo cuyo fruto es comestible.

güitite $\mathrm{m}$. Nombre de arbusto que echa un fruto pequeño de color amarillo o rojo, denominado uva, muy gustado por los pájaros. Se utiliza para cocimientos medicinales.

gusanillo $\mathrm{m}$. Enfermedad de la caña producida por un gusano diminuto, el cual la taladra.

\section{H}

habilitada adj. En el ganado vacuno dícese de la vaca cuando está preñada.

hablantín adj. Dícese de la persona que gusta hablar mucho.

hacer pipí loc. Orinar. Voz utilizada especialmente para referirse a los niños.

hacerse ref._el chancho loc. Tratar de disimular. // 2 _el gato bravo loc. Acaparar todo.

hacienda f. Extensión de terreno de más de mil hectáreas.

hachero adj. Dícese del que gusta lanzar indirectas o zaherir.

harina f. Lana.

hartado adj. Presumido, orgulloso, que gusta humillar a los demás.

heliotropo $\mathrm{m}$. Especie de lirio de caña larga de flores blancas y perfumadas. Crece a orilla de los ríos y quebradas o nacientes.

henchir tr. Llenar un recipiente.

hendija f. Organo genital femenino. // 2 Rendija.

hielera $\mathrm{f}$. Recipiente construido con material aislante utilizado para transportar agua con el fin de que ésta se mantenga fresca.

hijear intr. Echar retoños o hijos las plantas.

hijera f. Cortar de _. Cortar la hierba a mitad de altura.

hijo $\mathrm{m}$. Primer retoño de una planta. // 2 Rama de una planta luego de podada.

¿hijo de Dios! Interjección que denota susto, admiración o sorpresa.

hijuela $\mathrm{f}$. Hilera de plantas entre dos calles.

hilacha f. Enfermedad del café que desintegra la hoja hasta dejarla transparente.

hincarse ref. Ponerse de rodillas.

hocicón adj. Mentiroso.

hoja menuda m. Nombre de árbol de corteza muy dura, utilizado especialmente para leña.

hojear intr. Brotar las hojas de una planta.

hormiga f. _de fuego. Tipo de hormiga de color rojizo que se caracteriza por eyacular unos orines venenosos y causa ardores en la piel. // 2 _mandinga. Variedad de hormiga de color negro, cuya picadura es muy dolorosa.

hormigón m. Piedra muy porosa y quebrada, utilizada para regar sobre las calles en sustitución del asfalto. 
hornilla $\mathrm{f}$. Lugar debajo de la paila, donde se colocan diferentes materiales de desecho para encenderla y así hervir el caldo. // 2 Atizar la _. Colocar el material de desecho en la hornilla para calentarla.

horqueta $\mathrm{f}$. Varilla larga, generalmente de madera, cuyo extremo tiene forma de u cerrada y es utilizada para quitar la chira a las musáceas.

horquetear tr. Echar la planta de café sus primeras ramas.

horquetero $\mathrm{m}$. Persona encargada de vigilar la recolección del café, de entregar los cortes y de verificar que la junta se haya hecho correctamente.

huellar tr. Dícese del perro cuando empieza a seguir el rastro de la presa.

idiático adj. Maniático, obsesivo.

ingrido adj. Abstraído, absorto.

interior $\mathrm{m}$. En las casas rurales, el lugar donde se encuentra la letrina, generalmente afuera.

invierno $\mathrm{m}$. Estación lluviosa.

irse ref. _al otro potrero loc. Morir, fallecer // 2 _en la tira loc. Eyacular el hombre, alcanzar la mujer su orgasmo.

itabal $\mathrm{m}$. Terreno sembrado de itabos.

itabo m. Nombre de una planta de flor amarga pero comestible. Se utiliza como tapaviento en los sembradíos. La hoja suazada se utiliza para amarrar los tamales.

\section{$\mathbf{J}$}

jaba f. Estructura de barilla metálica o de palos o cedazo, sirve para encerrar principalmente aves y también conejos.

jabillo m. Nombre de árbol cuya corteza expide un líquido lechoso y ácido capaz de quemar la piel.

jabonero adj. Dícese de la persona que cambia de pareja frecuentemente.

jaibo $\mathrm{m}$. Tonto, torpe. Jerga juvenil.

jalado $\mathrm{m}$. Pálido, extenuado.

jalonazo m. Tirón. Acto de sentir una descarga eléctrica.

jama f. Comida.

jamar tr. Comer.

jamón m. Dícese de lo que se puede realizar fácilmente.

jamonero adj. Dícese de la persona que gusta aprovecharse de otros inferiores a él.

jaral $\mathrm{m}$. Mala hierba de hoja pequeña, redonda, y flor morada.

jarana $f$. Deuda.

jaranero adj. Dícese de la persona que no paga sus deudas.

jartón adj. Glotón.

jediondo adj. Hediondo. Voz usada para ofender. 
jeta $\mathrm{f}$. Boca.

jetón adj. Mentiroso, chismoso.

jicote $\mathrm{m}$. Nombre de la avispa productora de miel. // 2 _de mariola. Avispa amarilla y muy pequeña caracterizada por producir una miel muy dulce y medicinal. Se utiliza generalmente para el tratamiento de afecciones de los ojos.

jilguero $\mathrm{m}$. Nombre de pájaro cantor.

jincar tr. Punzar. // 2 intr. Tener relaciones sexuales.

jinocuabe $\mathrm{m}$. Nombre de árbol utilizado en el tratamiento de úlceras y enfermedades del cabello. jocote m. pl. Dedos de los pies.

jodedera $\mathrm{f}$. Impertinencia.

jogoto $\mathrm{m}$. Gusano grueso y blanco que se come las raíces de las plantas tiernas.

¡jueputa! interj. Una de las imprecaciones más usadas por los ticos.

jugado adj. Persona con mucha experiencia en asuntos amorosos.

jugar intr._de vivo (de peligroso) loc. Presumir.

jugársela loc. Correr un riesgo.

juma $f$. Borrachera.

jumo adj. Hebrio.

juntar tr. Recoger alguna cosa del suelo.

juntarse ref. Amancebarse.

jupa t. Cabeza.

jupear tr. Contactar la cabeza con la bola de fútbol.

jupón adj. Porfiado, desobediente.

justán m. Ver Chingo (acepción 3).

¡la sangre de Cristo! Interjección que denota asombro, susto o sorpresa.

labioso adj. Que tiene habilidad para decir o realizar cosas.

lagartillo m. Arbusto de tallo espinoso, cuya cáscara es de color azul o de color amarillo.

lana $\mathrm{f}$. Dinero.

lance $\mathrm{m}$. Oportunidad para entablar una relación amorosa.

lanilla $\mathrm{f}$. Especie de moho que se adhiere a las plantas, sobre todo en época de invierno.

largo adv. Lejos (La Universidad queda largo).

largueros Ver a /fajilla.

lata f. Cualquier vehículo automotríz viejo o en mal estado. // 2 Dar_. Enfadar, molestar.

latir intr. Ladrar. // 2 Presentir. (Me late que no va a venir).

lavadero $\mathrm{m}$. Desgaste en los terrenos irregulares producto de fuertes lluvias.

lechigüilla $\mathrm{f}$. Planta de unos cincuenta centímetros de altura muy resistente, utilizada para hacer escobas.

lengón adj. Lenguaraz.

lengua f. _de zorro. Cuchillo gastado. // 2 _de vaca. Arbusto de hojas peludas cuyo fruto es comestible. // 3 _larga. Persona chismosa. 
libra f. Billete de cinco colones.

limpio $\mathrm{m}$. Terreno preparado para el cultivo. // 2 Sitio donde se ha talado árboles o quitado maleza. // 3 Espacio de terreno nivelado donde se coloca el manteado para aporrear los frijoles.

lipidia f. Miseria extrema.

lomillar tr. Acción de preparar el terreno formando hileras abultadas para la siembra.

lucia $f$. Especie de lagartija lisa y muy escurridiza.

lumbrear tr. Ver hijera (corta de_).

luna f. de _. Loc adv. Malhumorado, de mal carácter.

lunanca f. Dícese del animal caballar que tiene una pata más larga que la otra.

luyir tr. Desgastar.

llantas f. pl. Gordura que se forma alrededor de la cintura.

llenar el barco loc. Dejar a una soltera en cinta. Registrada en Chachagua.

lloradero $\mathrm{m}$. Ver naciente.

\section{M}

macana f. Barra de madera o metal con una plancha de hierro en una de las puntas que sirve para gabetear. // 2 _s. Los dientes.

macuá f. Nombre de ave cuyo nido es muy famoso pues se cree tiene poderes sobrenaturales.

macuco adj. Dícese de la persona fuerte, fornida.

machete $\mathrm{m}$. Cuchillo ancho y corto utilizado para cortar la hierba a baja altura.

machetear tr. Cortar la hierba a baja altura.

machín m. Nombre de un pez de río de color blancuzco.

machira f. Instrumento formado de un pedazo de cedazo con dos varillas, una en cada extremo, para aporrear frijoles.

macho $\mathrm{m}$. De pelo rubio.

madero m. negro. Nombre de un árbol maderable, de corteza negruzca, resistente y hojas menudas. Se utiliza para postes de cercas.

madrear tr. Ofender.

maíz cogida de _. Recolección de las mazorcas del maíz. // 2 corazón del _. Parte central, blanca, del grano de maíz. // 3 cabellar el_. Echar pelo el maíz. // 4 arrancar_. Extraer la mata del maíz. // 5 doblar _. Acción de inclinar a la mitad la mata de maíz seca para dejar más tiempo el producto en el sembradío. // 6 lancear el _. Comenzar la planta del maíz a desarrollar la flor, que en esta etapa tiene forma de lanza. // 7 _amarillo. Variedad de maíz, cuyos granos son anchos y amarillos. // 8 gelado. Mazorcas de maíz que no logran el grado óptimo de desarrollo. // 9 _maicena. Variedad de maíz, cuya planta es de gran altura, la mazorca es delgada y larga, el grano es menudo y de muy buena calidad.

malanga $f$. Tubérculo que crece en terrenos pantanosos y su fruto es comestible.

maldoso adj. Malvado.

malmatarse ref. Herirse al caer.

mama lucia Loc. Dícese del hombre que no tiene barba. 
mamitas adj. Cobarde, chuchinga.

mamón adj. En el juego de fútbol, dícese del que mantiene la bola mucho tiempo en su poder u no la entrega a otro compañero.

mampuesto $\mathrm{m}$. Lugar en que se apoya el arma de fuego cuando se va a disparar.

mancha f. Agua que expelen los árboles o musáceas.

¡manda güevo! Interjección que denota desaprobación resentimiento o el colmo de una acción o hecho.

mandador $\mathrm{m}$. El encargado de vigilar y ordenar las labores de los peones, jornaleros o empleados de las maquilas.

mango m. Agarradera de algunos instrumentos agrícolas.

mano $\mathrm{m}$. Conjunto de frutos que configuran cada una de las partes del racimo de las musáceas.

manteado $\mathrm{m}$. Capota rectangular, generalmente de manta, que se coloca atando sus extremos a cuatro varillas y formando una especie de medio cilindro. Se utiliza para aporrear los frijoles.

maña f. Mala costumbre, hábito.

maquinilla f. Utensilio que se utiliza para afeitar. // 2 Utensilio que sirve para hacer punta a los lápices.

mariarrosa f. Nombre de árbol maderable.

marimacho adj. Hombruna.

marqueta $\mathrm{f}$. Trozo de hielo rectangular y de gran tamaño.

masa s. Parte de la máquina trituradora de la caña de azúcar con forma cilíndrica. Se mueve en forma circular impulsada por una correa movida por un motor.

masata $\mathrm{f}$. Variedad de garrapata. La de mayor tamaño.

mataburros m. pl. El diccionario.

matapalo $\mathrm{m}$. Planta enredadera que ataca y mata al árbol donde se extiende.

matar tr. _la culebra loc. Dejar pasar el tiempo.

matón m. Arbusto de tamaño mediano, mala hierba.

matricidio $\mathrm{m}$. Matrimonio.

maya t. Virus que afecta los cultivos como la caña, el frijol, el café, la papa, y otros.

mayarse ref. Marchitarse.

meco m. Hueco hecho en el trompo, por el punzón de otro trompo.

mechas f. pl. Cabello.

mejenga f. Fiesta. Registrada en San Antonio. // 2 Partido informal de fútbol.

mejorarse ref. Parir, dar a luz.

melcochón m. Pan simple, largo, blanco y de forma redondeada.

melindres adj. Melindroso.

mentar la madre (mentársela) loc. Ofender a alguien diciéndole hijo de puta.

mentira f. Sonido que se produce al hacer crujir los nudillos de los dedos.

mesa de noche $f$. Mueble que se tiene al lado de la cama.

meter tr. _carbón loc. Incitar a alguien contra otra persona, motivar. // 2 _las patas. Loc. Quedar una soltera embarazada.

metiche adj. Entrometido.

metido adj. Ver metiche. 
mezclilla f. Tela de algodón muy resistente, utilizada en la confección de pantalones o chaquetas. mezquino $\mathrm{m}$. Verruga.

mica f. Nombre de serpiente venenosa. // 2 Saco de manta.

miel f. _de caña. Producto de la caña de azúcar una vez que el caldo ha pasado el proceso de ralo a espeso.

milpa f. Maizal. // 2 Estar en _. En el juego del fútbol estar más adelante que la defensa contraria. moco m. Enfermedad que ataca las musáceas, a excepción del curraré. Hace que el racimo se madure prematuramente.

mocoso adj. Niño. Voz despectiva.

mocho $\mathrm{m}$. Dícese del cuchillo que le hace falta un pedazo.

molde $\mathrm{m}$. Pieza de madera con huecos en forma cilíndrica, en cuyo interior se chorrea la miel para formar la tapa.

molote m. Tumulto, alboroto.

montarse ref. Aprovecharse de otra persona.

monte m. Ver mota.

montear intr. Ir de cacería.

montura f. Silla de montar.

morada f. Paloma silvestre de color morado cuya carne es comestible.

morado $\mathrm{m}$. Billete de quinientos colones.

morruco $\mathrm{m}$. Pelo crespo y abundante.

mortandad f. Olor desagradable que despiden los cuerpos en descomposición.

moscón m. El encargado de vigilar a la pareja de novios. El que gusta ir detrás de las parejas sin ser invitado.

motete $\mathrm{m}$. Bulto, ropa empacada en desorden.

motosierra f. Sierra de motor.

mozote m. Arbusto cuyas semillas se adhieren con facilidad a la ropa. También es utilizado en los trapiches para clarificar el caldo. // 2 Persona que no se ajusta a las normas del grupo. muco $\mathrm{m}$. muca f. Dícese del toro o la vaca sin cuernos.

muchachada f. Conjunto de jóvenes.

mujer de patio loc. Mujer de la vida, prostituta.

mujerear intr. Conquistar mujeres.

mulata $\mathrm{f}$. Variedad de hormiga caracterizada porque cambia de color.

muriseco $\mathrm{m}$. Mala hierba cuya semilla se pega a la ropa. Se caracteriza porque la planta muere rápidamente pero se mantiene en pie.

nacencia $\mathrm{f}$. Gran cantidad de hierbas acabadas de nacer.

nacido $m$. Divieso.

natilla $\mathrm{f}$. Nata agria que se obtiene de la leche cruda y agria. 
nazareno $\mathrm{m}$. Nombre de árbol maderable cuya flor y corteza son de color morado. Su nombre se deriva de su particularidad de florecer en marzo por el tiempo de cuaresma.

negocio $\mathrm{m}$. Tienda, pulpería.

ni a putas loc. adv. Por nada, de ninguna manera.

nica $m$. Originario de Nicaragua.

nidal $\mathrm{m}$. Huevo que se coloca en el lugar donde pone la gallina para que ésta se acostumbre al nido.

niña f. Maestra de primaria o preescolar.

noviero adj. noviera. Dícese de la persona que es muy enamorada.

novillo $\mathrm{m}$. Dícese del ganado vacuno cuando el ternero tiene más o menos dos o tres años y ha sido castrado.

novios m. pl. Boda.

nueve días loc. adv. Celebración religiosa a los nueve días de fallecida una persona. Se rezan nueve rosarios para rogar por la salvación de su alma.

nuquear intr. En el boxeo, dejar al contrincante fuera de combate.

$\mathbf{O}$

obsequiar tr. Regalar.

obstinación f. Con furia, exasperado.

obstinado adj. Furioso.

obstinar tr. Enfurecer, desesperar.

ojo de gato $\mathrm{m}$. Enfermedad parecida a la chasparria que se caracteriza por desintegrar en forma de ruedas las hojas del cafeto, hasta hacerlas caer.

olote m. Parte central de la mazorca de maíz donde van incrustados los granos.

olla de carne f. Plato que se obtiene del cocimiento de verduras con carne y caldo.

ollejo m. Cáscara del grano de maíz que se suaviza al ser cocido. Variante: pellejo.

onza f. Moneda correspondiente a diecisiete colones. Término en vías de extinción.

opilada adj. Dícese de la gallina cuya digestión no funciona.

orear tr. Buscar oro en forma artesanal.

oreja $\mathrm{f}$. Pastel tostado con azúcar cristalizado por encima, y de forma cilíndrica.

orejear tr. Escuchar disimuladamente asuntos ajenos.

orinarse adentro loc. Dejar a una soltera encinta.

$\mathbf{P}$

paca $\mathrm{f}$. La policía. Término despectivo.

pachanga $\mathrm{f}$. Fiesta, diversión.

pacho $\mathrm{m}$. Vergüenza, bochorno. Hecho o acción motivo de burla.

pachotada $\mathrm{f}$. Brusquedad, respuesta tosca, patochada.

pachotero adj. Dícese del que gusta decir pachotadas.

pachuca $f$. Cartera de la mujer. 
pachuco adj. Persona cuyas costumbres, hábitos y forma de actuar son rechazados por el medio en que vive.

paja f. Habla o discurso de poca importancia.

pajoso adj. Dícese del que habla mucho y el contenido de sus palabras es de poca importancia. // 2 Persona que promete y no cumple.

paila f. Estanque que mide hasta dos metros de diámetro. Se utiliza para cocer el caldo de la caña. // 2 _mielera. Recipiente en el que el caldo se transforma en miel para ser trasladado a los moldes.

pala ancha f. Tipo de pala caracterizada por ser muy ancha y utilizarse, especialmente, en la raspa. Variante: maizola.

palabrear tr. Realizar un trato de palabra y no con documentación.

palear tr. Preparación de un terreno para cultivarlo, mediante la utilización de una pala ancha.

paleta $\mathrm{f}$. Instrumento de madera, ancho en un extremo y delgado en el otro, de unos 15 centímetros de largo. Se utiliza para quitar el barro a la pala.

palín m. Tipo de pala, larga y muy angosta. Se utiliza exclusivamente para hacer huecos.

palmito $\mathrm{m}$. Parte más blanca de la palmera, la cual es comestible. // 2 adj. Variedad de queso blanco elaborado en capas.

palo m. Árbol.

palote m. Tallo del plátano. // 2 Parte central del tallo del plátano utilizada como alimento para el ganado.

pandereta $\mathrm{f}$. Persona fanática a la religión pero que no es católica.

pantalón m. _campana. Estilo de pantalón masculino de corte recto y de gran anchura en el ruedo. Prenda y acepción en vías de extinción. // 2 _picapollo. Dícese del pantalón masculino que queda muy corto.

panteón m. Cementerio.

panteonero $\mathrm{m}$. El encargado de cuidar el panteón.

panza de gato. Ver zacate cansagente.

panzona adj. Mujer embarazada. // 2 Aplícase también a los animales cuando la hembra está preñada.

paño m. Toalla.

papa f. Tener la _en la mano loc. Disponer de algo sin tener dificultad.

papada $\mathrm{f}$. Carne que cuelga debajo del cuello del cerdo.

papín m. Comida hecha de maíz con leche.

paqueteado adj. Dícese de lo que no es original o legítimo.

paquetear tr. Estafar, alterar clandestinamente.

pará m. Nombre de pasto que crece horizontalmente, de bejuco largo.

paracaidista adj. Persona que gusta ir a las fiestas privadas sin ser invitado.

paral m. pl. Parte del tejido de los canastos que se adhieren al gollete. // 2 Palos verticales de los costados de la carreta.

pasamano $\mathrm{m}$. Entrada pequeña a un terreno, exclusivamente para que pasen personas.

pata f. _de chancho. Instrumento utilizado en carpintería y en construcción de cercas. Tiene forma de pezuña de cerdo. // 2 _de gallo. Forma de sembrar las hileras del café de menera triangular. // 3 _plana. Dícese del pie que no tiene curva por debajo. 
patio m. Espacio abierto detrás de las casas urbanas. En las casas rurales el patio está en frente. patriota $\mathrm{m}$. Hierba de color entre morado y rojizo.

pecho amarillo $\mathrm{m}$. Nombre de pájaro cuya característica principal es que es amarillo y la hembra es de color café.

pedo $\mathrm{m}$. Enfermedad que ataca al maíz y forma un hongo color negro, aniquilando la mazorca. peineta f. Tres o más granos unidos. // 2 Parte trasera de la montura donde está atada la grupera. pelero $\mathrm{m}$. Cualquier tipo de mantilla suave que sirve de sudadera a las bestias. // 2 Estar como un _. Loc. Sucio.

pelo m. _de gato. Llovizna.

pergamino $\mathrm{m}$. Grano de café ya extraído de la cáscara, pero revuelto con ella.

perica $\mathrm{f}$. Miel en su punto para la preparación de dulce.

perlita $\mathrm{f}$. Primera etapa de desarrollo de la mazorca de maíz.

perro $\mathrm{m}$. Gancho de hierro con un mango de madera que sirve para rodar las tucas.

peseta $\mathrm{f}$. Moneda de veinticinco céntimos.

pezón $\mathrm{m}$. Parte que une el fruto a la mata.

pica $\mathrm{f}$. Acto de cortar el monte bajo. // 2 Espacio que se abre en la montaña para ingresar a ella. picar tr. Romper el terreno con el pico.

picoretear tr. Delatar.

picoreto adj. Delatador, lenguón.

pichel m. Cara.

pichichío m. Nombre de arbusto cuyo fruto es amarillo y se usa en el tratamiento de la cinocitis.

pichinga f. Recipiente para transportar líquidos. Su forma es generalmente cuadrangular.

pijearse ref. Drogarse.

pila f. _de caldo. Estanque rectangular, generalmente de madera, donde se hecha el caldo de la caña.

pilonear tr. Aporcar el maíz, cubriendo únicamente la raíz de la planta.

pinche adj. Tacaño.

pinolillo m. Bebida hecha de maíz tostado. Registrado en Chachagua.

piña f. Conjunto de frutos unidos que configuran las diferentes partes del producto.

pipa f. Variedad de coco cuyo fruto se caracteriza por producir gran cantidad de agua, en su interior, la que tiene un sabor muy agradable.

pipiriciego adj. Corto de vista.

piraña f. Ladrón, ratero. // 2 Dícese de la mujer que tiene mucha experiencia en asuntos amorosos.

pisar intr. Tener relaciones sexuales. // 2 Cubrir el gallo a la gallina.

pisuicas m. Satanás.

pitear intr. Florear la caña de azúcar o el maíz.

pitilla $\mathrm{f}$. Nombre de pasto utilizado para forrajes.

pizón $\mathrm{m}$. Varilla pesada utilizada para sacar los postes. // 2 Dícese del hombre que gusta realizar excesivamente el coito.

plancha f. pl. Pies.

plantelillo $\mathrm{m}$. Ver limpio. 
plástico adj. Dícese del joven que por su forma de vestir, hablar o actuar aparenta ser de la clase alta. Término despectivo.

plata f. Dinero.

platal m. Dineral.

platanal $\mathrm{m}$. Campo sembrado de plátano.

plátano m. Variedad de musácea más grande que el banano. // 2 _criollo. Variedad de plátano cuya planta es gruesa y su fruto grande. // 3 _felipita. Variedad de plátano. // 4 limune. Variedad de plátano que se caracteriza por ser grande y muy dulce. // 5 _manzana. Variedad de plátano que se caracteriza por ser pequeño y muy dulce.

platero m. Artefacto de madera utilizado para escurrir los trastos.

platudo adj. Con mucho dinero.

playón m. Lecho seco de un río.

plaza f. Terreno plano y con gramilla utilizado para practicar el fútbol.

polada f. Actuación de mal gusto.

polaquear intr. Vender de casa en casa casi siempre al crédito.

polca f. Ir en _loc. Ir en las ancas, en la parte posterior del jinete; ir en la parte posterior de la motocicleta.

polo adj. Término despectivo para el campesino. // 2 Dícese de la persona cuya forma de actuar vestir y hablar no es la aceptada por el grupo.

poloncho adj. Variante de polo.

poni poni f. Nombre de pájaro de color café con morado. El nombre se deriva del sonido del pájaro. Registrado en Chachagua.

poró $\mathrm{m}$. Nombre de varias especies de árboles fabáceos. Se utiliza para dar sombra a las plantas de café.

portal m. Simulacro a través de figuras esculpidas de la época y nacimiento de Jesucristo.

posta $\mathrm{f}$. Carne sin hueso, la de mejor calidad.

postrera f. La última leche ordeñada de la vaca. Generalmente esta leche es color amarillo y productora de natilla.

poza $\mathrm{f}$. Represa pequeña de agua en forma natural o artificial formada en los ríos donde se baña la gente como medio de recreación.

pozol m. Maíz que al ser cocinado no suelta el ollejo.

precisar tr. Urgir.

prensada adj. Cerveza combinada con licor.

prueba f. Porción de miel que se extrae de la paila para determinar si está en su punto.

pujo $\mathrm{m}$. Enfermedad de la gallina que se caracteriza por una inflamación en la cresta y los ojos en forma de pelota.

pulpería $\mathrm{f}$. Tienda de comestibles.

pulpero $\mathrm{m}$. El dueño que vende en la pulpería.

pulsear tr._el calzón loc. Incitar a una mujer para llevarla al acto sexual. Jerga juvenil.

punto $\mathrm{m}$. Estado óptimo de la miel para ser chorreada a los moldes.

punzón m. Herramienta utilizada para capar el café.

puño m. Ver mango.

purete $\mathrm{m}$. De poco valor. 
purisco m. Botón de la flor del frijol.

purisquear intr. Echar el frijol la flor, conocida como purisco.

puta f. Prostituta. Variante: turra.

putero $\mathrm{m}$. Ver chispero.

\section{Q}

¿qué esperanza! loc. Interjección que denota disconformidad ante una acción o la lentitud con que se realiza una acción.

¡qué tiene! loc. ¿Qué importa!

quebrantado adj. Dícese del bebé que por haber sido sentado antes de los tres meses (según la creencia popular) se le desajusta el primer hueso de la columna. Sus heces son de color verde.

quedó $\mathrm{m}$. Nombre de juego infantil en el cual se elige a un perseguidor que cambia por perseguido cuando logra tocar a otro y decirle: quedó.

quelite $\mathrm{m}$. Las hojas tiernas de la planta de chayote.

quema f. Época en que se queman los terrenos para eliminar las malezas. Generalmente es en marzo y abril.

quemar tr._el cachiflín loc. Sufrir una persona por causa de la infidelidad conyugal de su pareja.

quemarla loc. Fumar marihuana.

quicio $\mathrm{m}$. Grada que está colocada debajo de una puerta.

quino $\mathrm{m}$. Nombre de árbol de hojas menudas que son muy resistentes para caer. Tiene un olor agradable y la cascara de la corteza se utiliza para cocimientos medicinales.

quinta $\mathrm{f}$. Ver hijuela.

quisneto adj. Inclinado, desnivelado.

\section{$\mathbf{R}$}

rabo m. Trasero. // 2 _pelado. Especie de zorro que tiene muy poco pelo. // 3 _de zorro. Nombre de mala hierba que crece en forma de rabo y la flor se adhiere con facilidad a la ropa.

rajón adj. Que gusta hacer falsos alardes de su persona.

rana f. Ver libra.

raspa f. Cortar el monte a baja altura. // 2 Acción de raspar el terreno. Época cuando se prepara el terreno para cultivarse, se realiza exclusivamente con la pala.

raspadita f. Juego de lotería donde el jugador descubre su suerte una vez que raspa parte del cartón.

raspado adj. Sin dinero, en la miseria total.

rastrojo, restrojo $\mathrm{m}$. Terreno en descanso o abandono. // 2 Terreno donde anteriormente se había sembrado maíz o frijoles.

ratón $\mathrm{m}$. Músculo del brazo, bíceps.

ratoncillo $\mathrm{m}$. Nombre de árbol maderable, de tronco rojizo y hoja menuda. 
recantear tr. Acción de observar las primeras tablas. refundidero $\mathrm{m}$. Lugar de difícil acceso. regar tr. Esparcir granos en el suelo. rejoya $\mathrm{f}$. Parte más baja y fértil de un terreno. remangar tr. Quitar la basura de los surcos una vez que la caña ha sido recogida. repasto $\mathrm{m}$. Campo donde se ha sembrado pasto para forraje. repela f. Última etapa de la cogida de café, cuando se coge ajecho. repelador adj. Persona que acostumbra coger el mejor café de las matas que están fuera de las matas o corte asignado.

repelar tr. Recolectar el mejor café de las matas que están fuera de la calle o corte asignado. repollito $\mathrm{m}$. Nombre de mala hierba cuya flor se adhiere con facilidad a la ropa. resiembra f. Segunda siembra que se realiza cuando el cultivo no nace o no se desarrolla. restrojear tr. Recoger los granos que quedan una vez realizada la recolección de un cultivo. resumirse ref. Filtrarse un líquido.

rodea $\mathrm{f}$. Momento en que el frijol es transportado del campo al aporreadero. rodear tr. Acción de llevar el frijol al aporreadero. rolear intr. Dormir. ronda $\mathrm{f}$. Espacio entre el límite de una propiedad rural y el camino público. rotana $\mathrm{m}$. Variedad de pasto. rula f. Tipo de machete quebrado a la mitad. Variante: fizga.

saber cómo anda el arroz loc. Saber el secreto, enterarse de todo. saca f. Fábrica de licor clandestino. salveque $\mathrm{m}$. Mochila. sauco $\mathrm{m}$. Nombre de arbusto medicinal cuyas flores son blancas. seguro m. Establecimiento de atención médica perteneciente a la Caja Costarricense de Seguro Social.

sercha f. Armazón de madera donde se coloca la alfajilla. servidumbre $\mathrm{f}$. Ver pasamano. sirrí amarillo $\mathrm{m}$. Nombre de árbol cuya hoja se parece a la palmera. sobado m. Dulce suave hecho de la miel de caña que aún no está en su punto. sobo m. Masturbación.

socador $\mathrm{m}$. Varilla con horqueta o palo recto con dos grapas en una de las puntas, utilizado para socar el alambre en la construcción de cercas.

socar tr. Acción de comprimir la tierra que queda entre el hoyo y el poste para darle firmeza. socola $\mathrm{f}$. Terreno o bosque que ha sido derribado para cultivarlo.

socolar tr. Derribar un bosque para cultivar el terreno o convertirlo en repasto. Variante: romper sabana.

soda $\mathrm{f}$. Establecimiento de menor tamaño que un restaurante, donde se venden comidas y bebidas. 
sornia f. Planta medicinal usada en el tratamiento de los parásitos.

soterré $m$. Nombre de pájaro de color café.

¡suave! Interjección que se utiliza para hacer que alguien se detenga.

\section{T}

tablado $\mathrm{m}$. Palco provisional.

tacotal m. Campo cubierto por un matorral espeso.

tamal m. _mudo. Masa de maíz condimentada con manteca que envuelta en hojas de plátano se cocina. // 2 _asado. Torta de maíz condimentada con leche agria, azúcar y queso. // 3 _de chancho. Torta de maíz cocida a la cual se le agrega papa, chile dulce, arroz condimentado y trocitos de carne de cerdo. // 4 _ de elote. Torta de maíz tierno y azúcar o dulce.

tamuga f. Conjunto de dos pares de tapas de dulce. // 2 Persona gruesa y pequeña.

tanate m. Montón. // 2 Pleito, lío.

tapa f. _de dulce. Comprimido de dulce, hecho de la miel de caña de azúcar, en forma de cono y endurecido en moldes que le dan tal forma.

tapaviento $\mathrm{m}$. Seto formado de arbustos de ramas tupidas.

tarea f. Cantidad de caña que se tritura para obtener determinado número de tamugas.

targuá m. Nombre de árbol cuyas hojas son verdes y rojizas. Se caracteriza por eyacular una mancha rojiza utilizada para algunas curaciones de enfermedades, como las úlceras.

tatas m. pl. Padres de familia.

tatica m. Abuelo.

temblor $\mathrm{m}$. Sismo de poca magnitud.

templado adj. Excitado sexualmente, que se excita sexualmente con frecuencia y facilidad.

tequioso adj. Travieso, fogoso.

tercón m. Una de las partes de la sierra.

terreno m. _a medias. Dícese de aquel terreno cuyo cuidado, cultivo de la tierra y frutos se comparten por igual entre dos personas. // 2 _al tercio. Modo de cultivar un terreno, de tal forma que el propietario recibe la tercera parte del producto total del cultivo. // 3 _encharralado. Campo cubierto de maleza. Variante:_enmontado.

teta $\mathrm{f}$. Seno.

¡tica! Interjección usada para llamar la vaca.

¡tico! Interjección usada para llamar el ternero.

tigrillo m. Nombre de mamífero carnívoro de color gris.

timba f. Estómago muy grande.

tolas adj. Testículos.

tolva $\mathrm{f}$. Voz despectiva para designar la boca.

topar tr. Acción de ayudar a alguien en la recolecta de una hilera de cafeto, comenzando por el extremo contrario.

torbó $\mathrm{m}$. Grano viejo y apolillado.

toronjas $\mathrm{f}$. pl. Tetas. 
tórsalo m. Miembro viril. // 2 Nombre de gusano parásito que ataca a los animales y a veces al hombre el cual produce abultamientos en la piel y fuertes dolores.

tortolocuilo m. Gusano muy peludo que abunda en los cafetales. Se caracteriza porque su picadura es muy dolorosa y causa fiebres y alergias.

tostada f. Tortilla frita con queso.

traba $\mathrm{f}$. Una de las partes de la sierra.

tragón m. Dícese de la persona que es muy estudiosa.

tranca $\mathrm{f}$. Cerrojo o picaporte.

tranquera f. Empalizada compuesta de dos postes clavados en tierra, los cuales tienen un hueco por donde se pasan y se sostienen horizontal y transversalmente tres o cuatro varillas.

transar tr. Caerle bien a alguien. Tenerle simpatía amorosa a alguien.

troja f. Lugar cubierto donde se almacenan los granos, herramientas y, en general, lo que tiene que ver con agricultura.

trompa f. _de chacho Avispa negra y grande que fabrica su panal, el cual tiene forma de cono. Se caracteriza por ser muy agresiva.

trompilla f. Argolla metálica que se coloca por medio de un alambre en las fosas nasales del cerdo para que éste no escarbe.

tuca $\mathrm{f}$. Tronco de un árbol para ser aserrado.

tuete m. Arbusto muy común en los potreros, de flor blanca que despide un aroma agradable.

turra f. Prostituta.

tuza f. Envoltura de la mazorca de maíz.

uña f. Grupo de raíces exteriores de la planta de maíz, las cuales dan firmeza a ésta. ¡upe! Interjección usada para averiguar si hay alguien en casa.

urrú m. Tronco podrido.

vainica $\mathrm{f}$. Vaina verde o madura del frijol. // 2 Tipo de frijol destinado a la producción de vainas y no del grano.

vainiquear intr. Empezar vaina la planta de frijol.

vaniada adj. Milpa que ha perdido la cosecha en su totalidad. Cosecha no cuajada.

vaniar intr. Acción de perderse la cosecha del maíz.

vaquita $\mathrm{f}$. Insecto de color rojo con blanco, o azul con blanco. Se caracteriza por comerse las hojas del frijol.

vara (de la tranca) f. Varilla que se coloca verticalmente para formar la tranquera. //2 blanca.

Nombre de un árbol de gran altura cuya flor es azul. 
varilla f. _de aporrear. Vara larga y delgada en la punta, utilizada para extraer los granos de frijol de las vainas.

vástago $\mathrm{m}$. Tallo del plátano.

vena f. _de plátano. Parte central y delgada de la hoja del plátano. En tiras se utiliza para amarrar tamales.

ventearse ref. Resfriarse.

viaje $\mathrm{m}$. Un _de. Conjunto de personas o cosas (Van a despedir un viaje de empleados).

virgen $\mathrm{f}$. Barra de hierro que sostiene las del trapiche.

virote $\mathrm{m}$. Parte de la planta de las musáceas, donde se adhieren las frutas y el chirote.

vistada f. Panorama.

vivazo adj. Presumido, orgulloso. Término despectivo. Jerga juvenil.

volador $\mathrm{m}$. Parte del trapiche de bueyes, atado al yugo, se mueve en forma circular y su función es hacer girar las masas para triturar la caña.

volar_chafirra. Trabajar con el cuchillo en el campo, cortar maleza.

voltea $\mathrm{f}$. Acción de talar utilizando el hacha o la sierra de motor.

vuelto $\mathrm{m}$. Sobrante de dinero luego de cancelar al vendedor.

vulgar adj. Obsceno.

vulgaridad $\mathrm{f}$. Obscenidad.

\section{Y}

yodo $m$. Café.

yuyo $\mathrm{m}$. Hongo que se forma en los dedos de los pies. // 2 Persona fastidiosa o que es inoportuna.

\section{$\mathbf{Z}$}

zacate m. _brama. Variedad de zacate, de bejuco muy menudo. // 2 _cansagente. También conocido como panza de gato. Mala hierba caracterizada por ser de bejuco tupido y duro y por tanto difícil de cortar. // 3 _de guinea. Variedad de zacate que se caracteriza por ser de gran altura, tener el tallo grueso, en forma de caña y echar flor en forma de veraliz. // 4 _de limón. Variedad de zacate que se caracteriza por crecer en macolla y servir para cocimientos medicinales. // 5 _estrella. Variedad de zacate que crece horizontalmente y es muy resistente a la sequedad. Mala hierba cuando crece en los sembradíos. // 6 _gigante. Variedad de zacate de gran altura, que ortiga y es difícil de arrancar. // 7 _tingrá. Variedad de zacate que se siembra en época veraniega a través de regadío. Se utiliza para alimentar al ganado.

zapoyol m. Variedad de perico muy pequeño de color verde claro.

ziper $\mathrm{m}$. Cremallera.

zoque $\mathrm{m}$. Dícese del hombre o mujer que besa y abraza, como aventura amorosa, o en calidad de relación formal a su pareja.

zorrear intr. Conquistar mujeres. // 2 Ejercer la prostitución.

zumo m. Líquido inflamable que contienen las cáscaras de los cítricos. 


\section{Notas}

1. Aprovecho la oportunidad para agradecer profundamente al Dr. Miguel Ángel Quesada Pacheco, quien hizo la corrección del trabajo y dio las sugerencias pertinentes para realizar la investigación.

\section{Bibliografía}

Agüero, Arturo. 1962. El español de América y Costa Rica. San José: Atenea.

1964. "El español de Costa Rica y su atlas lingüístico". Presente y futuro de la lengua española I. Actas de la Asamblea de Filología del I Congreso de Instituciones Hispánicas, 135-52. Madrid.

Arroyo, Víctor. 1971. El habla popular en la literatura costarricense. San José: Departamento de Publicaciones de la Universidad de Costa Rica.

Comisión Nacional de División Territorial Administrativa 1989. División territorial administrativa de la República de Costa Rica. San José: Imprenta Nacional.

Coseriu, Eugenio. 1977. "La geografía linguiística”. El hombre y su lenguaje, 103-58. Madrid: Gredos.

Gagini, Carlos. 1892. Diccionario de barbarismos y provincialismos de Costa Rica. San José: Tipografía Nacional.

1918. Diccionario de costarriqueñismos. San José: Imprenta Nacional.

Gaínza, Gastón. 1976. "El español de Costa Rica. Breve consideración acerca de su estudio". Revista de Filología y Lingüística de la Universidad de Costa Rica. 2 (4): 79-84.

Gómez Córdoba, Carlos E. 1975. Vocabulario cafetero de la provincia de Cartago. Tesis de licenciatura: Universidad de Costa Rica.

Jaén García, Xinia. 1989. Léxico de la cultura del maíz en el distrito de Sardinal, Carrillo, provincia de Guanacaste. Tesis de maestría: Universidad de Costa Rica.

Lapesa, Rafael. 1983. Historia de la lengua española. Madrid: Gredos.

Meza, Hortensia. 1980. El habla de los sabaneros liberianos y tilaranenses. Estudio léxico-semántico con anotaciones fonológicas, morfológicas y sintácticas. Tesis de licenciatura: Universidad de Costa Rica. 
Quesada Pacheco, Miguel Ángel. 1981. Análisis sociológico lingüístico del español de San Gabriel, Monterrey y La Legua de Aserrí. Tesis de licnciatura: Universidad de Costa Rica.

1988. "La geografía lingüística en Costa Rica: sus problemas y sus logros". I Seminario de Tradición e Historia Oral [Universidad de Costa Rica, 3 y 4 de diciembre de 1987], 45-56. Universidad de Costa Rica: Oficina de Publicaciones.

1992a. El español en Costa Rica: historia de sus estudios filológicos y lingüísticos. San José: Editorial Fernández Arce.

1992b. Atlas lingüístico-etnográfico de Costa Rica. Cuestionario. San José: Editorial Nueva Década.

1992c. "Pequeño atlas lingüístico de Costa Rica". Revista de Filología y Lingüística de la Universidad de Costa Rica". 18(2): 85-189.

Rodríguez B., Edgar. 1977. El lenguaje hampesco costarricense. Tesis de licenciatura: Universidad de Costa Rica.

Román J., María N. 1976. El uso del español en Desamparados de Alajuela. Tesis de licenciatura: Universidad de Costa Rica.

Solano, Yamileth. 1986: "Una variación lingüística en el habla costarricense". Revista de Filología y Lingüística de la Universidad de Costa Rica 12(1):133-43.

Vindas Chaves, Francisco. 1971. Vocabulario del banano. Tesis de licenciatura: Universidad de Costa Rica.

Wilson, Jack. 1970. A Generative Phonological Study of Costa Rican Spanish. Tesis doctoral: Universidad de Michigan.

Zamora Araya, Xinia. 1977. El léxico de los oficios en el habla popular costarricense. Tesis de licenciatura: Universidad de Costa Rica.

Zamora Munné, Jorge Guitart. 1988. Dialectología hispanoamericana. Teoría, descripción, historia. Salamanca: Publicaciones del Colegio de España.

Zamora Vicente, Alonso. 1985. Dialectología española. Madrid: Gredos. 